\title{
COMPLETE UTERINE INVERSION DURING LOWER SEGMENT CAESAREAN SECTION
}

\author{
Mubina Begum Bijapur', Birajdar Sanjeev Bhimeshankar², Nazeer Ahmed K³, Rajendra Kumar B4
}

${ }^{1}$ Assistant Professor, Department of Anaesthesia, Al-Ameen Medical College, Vijayapur, Karnataka, India. ${ }^{2}$ Associate Professor, Department of Anaesthesia, Al-Ameen Medical College, Vijayapur, Karnataka, India. 3 Professor, Department of Anaesthesia, Al-Ameen Medical College, Vijayapur, Karnataka, India. 4 Professor, Department of Anaesthesia, Al-Ameen Medical College, Vijayapur, Karnataka, India.

HOW TO CITE THIS ARTICLE: Bijapur MB, Bhimeshankar BS, Ahmed NK, et al. Complete uterine inversion during lower segment caesarean section. J. Evolution Med. Dent. Sci. 2018;7(28):3262-3263, DOI: 10.14260/jemds/2018/734

\section{PRESENTATION OF CASE}

We describe a case of acute uterine inversion that occurred during a lower uterine segment caesarean section in a 20year-old primigravida under subarachnoid block that was managed successfully. During the extraction of the placenta with controlled cord traction inversion of uterus was observed. After several unsuccessful attempts, the inversion was corrected by gradual reversion of the uterus done by rolling the lower edge over the uterine fundus (first part to invert, first reverted) followed by extraction of the placenta. A blood loss of about $1000 \mathrm{~mL}$ was estimated and corrected with two pints of compatible blood transfusion. The patient was shifted to the postoperative room in a stable condition. The postoperative period was uneventful. We concluded that uterine inversion is a serious complication, of which both the anaesthesiologist and the obstetrician should be aware of since its prompt diagnosis and early management are of utmost importance in preventing maternal morbidity and mortality.

\section{DIFFERENTIAL DIAGNOSIS}

Inversion of uterus through the uterine incision during caesarean section is a rare life-threatening obstetrics emergency. In cases of prolonged uterine inversion, haemodynamic instability and shock which are often out of proportion to the degree of blood loss, have been reported as serious sequel. We describe a case of acute uterine inversion that occurred during lower uterine segment caesarean section, which was managed successfully under regional anaesthesia i.e. subarachnoid block.

\section{PATHOLOGICAL DISCUSSION}

A 20 years old primigravida, weighing $57 \mathrm{kgs}$ and height 157 cms with bilateral pedal oedema and pallor was posted for emergency lower segment caesarean section at 38 weeks under regional anaesthesia (subarachnoid block). Preoperative history was unremarkable. She had received vitamin supplements during pregnancy. Pre-anaesthetic examination, pulse rate of 102 beats per minute, regular and blood pressure of $108 / 68 \mathrm{mmHg}$ and $\mathrm{SpO} 2$ of $98 \%$ on room air. Review of systems was normal. Laboratory investigations,

'Financial or Other Competing Interest': None.

Submission 29-05-2018, Peer Review 23-06-2018,

Acceptance 29-06-2018, Published 09-07-2018.

Corresponding Author:

Dr. Mubina Begum Bijapur,

C/o. Dr. Nazeer Ahmed Jeugal,

H. No. 1485/A, Shaikh Colony,

$2^{\text {nd }}$ left Cross, J. M. Road, Vijayapur,

Karnataka, India.

E-mail: mubeen1983@hotmail.com drradharaman@yahoo.co.in DOI: $10.14260 / \mathrm{jemds} / 2018 / 734$ (c) (1) () $\Theta$ haemoglobin $8 \mathrm{gm} \%$ and other investigations were within normal limits. Monitors were connected and intravenous cannula 18-G was secured in left upper limb and preloading with $500 \mathrm{~mL}$ of ringer lactate was done. Subarachnoid block with $2 \mathrm{~mL}$ of injection Bupivacaine $0.5 \%$ heavy was injected at L3-L4 space and block up to T4 was achieved. Delivery of baby was uneventful. After extraction of baby, 10 units of Oxytocin was administered. Gentle cord traction was applied in order to remove the placenta following which complete inversion of uterus through the uterine incision occurred with the placenta remaining firmly attached to the uterine fundus with blood collection in between uterine bed and placenta. The oxytocin infusion was stopped. The inverted uterus was exteriorised at once and placenta was manually removed. After several attempts for uterine reversion lasting for less than 5 minutes, reversion of uterus was finally achieved by gradually rolling the lower most part of posterior edge over the uterine fundus. During the repositioning, the BP dropped to $80 / 40 \mathrm{mmHg}$ and pulse $178 / \mathrm{min}$. The uterus was repositioned intraabdominally and uterine closure was done. Injection methylergometrine $0.2 \mathrm{mg}$ administered intramuscularly to maintain the uterine contractions along with 20 units of oxytocin infusion. Another IV line was secured in right upper limb with 18G intravenous cannula and 2 units of compatible fresh blood were transfused. Blood loss was estimated to be around $1000 \mathrm{~mL}$. After the end of caesarean section $0.8 \mathrm{mg}$ tablet of Misoprostol was administered per rectally. Patient was shifted to postop ward with pulse rate of 108 beats/min and BP of $108 / 72 \mathrm{mmHg}$. The postoperative period was uneventful. Patient was discharged from hospital on $7^{\text {th }}$ postoperative day.

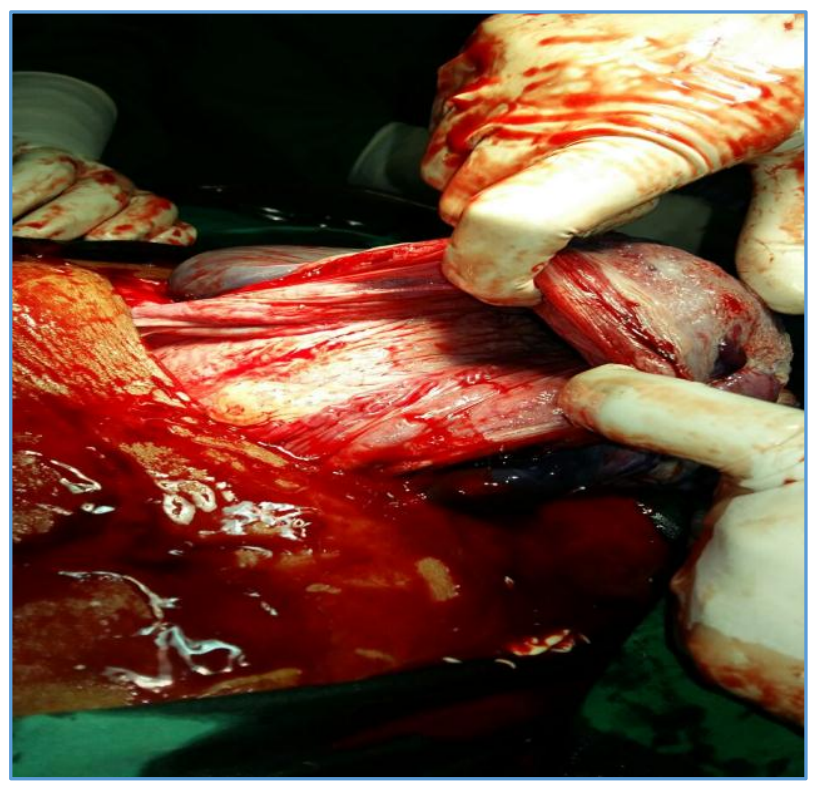

Figure 1 


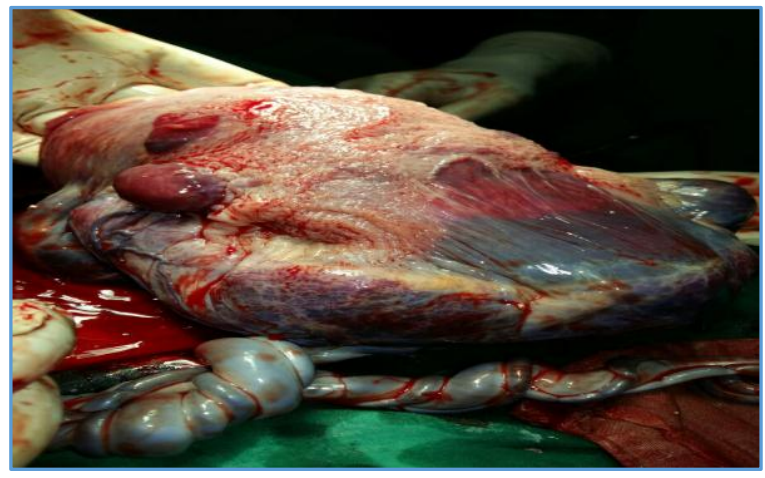

Figure 2

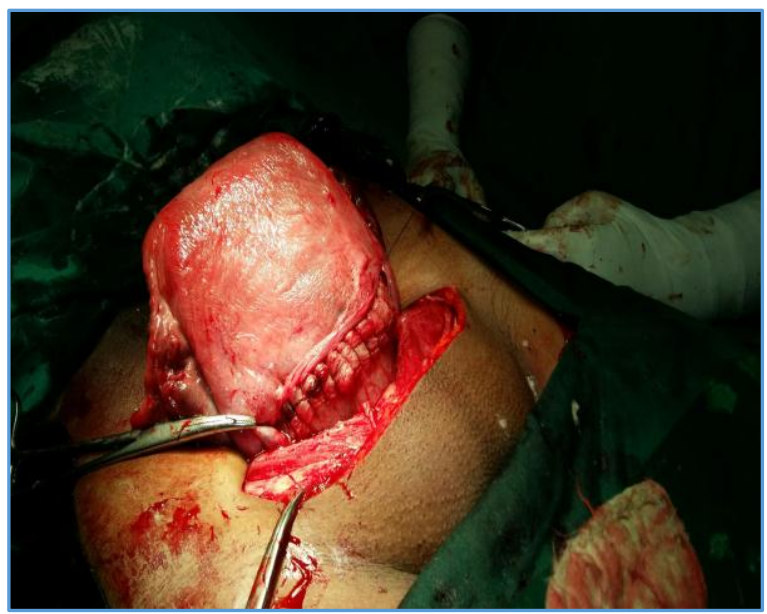

Figure 3

\section{DISCUSSION OF MANAGEMENT}

The exact incidence of uterine inversion during caesarean delivery is not known. It seems to be an extremely rare complication.(1,2-7) The reported incidence is one out of $1860,(8)$ much lower than that of following vaginal delivery, but we believe that this is overestimated because it is the first case reported in our department in the last year. The causes of this complication remain unclear. Fundal insertion of the placenta,(9) inherent weakness of the uterine musculature, $(2,3)$ the administration of oxytocin, in particular when given as a bolus $(10,11)$ and traction of the cord with the placenta, either partially or completely attached to the uterus (adherent placenta) ${ }^{(11,12,5)}$ could be probably contributing factors of this complication. The principal features of this complication are haemorrhage and shock which is often profound and out of proportion to the degree of blood loss. The blood loss depends on the inversion-reversion interval and can lead to serious haemodynamic instability. $(10,13,14)$ It has been postulated that hypotension and shock may be neurogenic in origin, owing to the traction on the patient's infundibulopelvic ligaments or secondary to peritoneal or broad ligament stretching.(11) Afferent impulses are thought to cause a vasovagal reaction leading to cardiovascular depression.(8) However, given that the patient is under anaesthesia, either general or regional, the neurogenic element of shock should be considered as eliminated,(9) so the blood loss remains the main reason for the patient's haemodynamic instability in our case. Management of uterine inversion during caesarean section is usually simple, if diagnosed promptly within a few minutes.
In our case, controlled cord traction was followed immediately by complete inversion. The firm fundal insertion of the placenta and the cord traction, although controlled and gentle could have been the contributing factors. Prompt diagnosis and re-inversion of the uterus facilitated a successful outcome. In cases of prolonged inversion to re-inversion interval, careful vigilance of the vital signs with anticipation of haemodynamic instability and bleeding is imperative.

\section{FINAL DIAGNOSIS}

Uterine inversion during caesarean section is a serious and unexpected obstetric complication, of which both the obstetrician and anaesthesiologist should be aware of. Prompt diagnosis and early uterine reversion without any delay are the key in management of this life-threatening obstetric complication.

\section{REFERENCES}

[1] Kriplani A, Relan S, Roy KK, et al. Complete inversion of the uterus during caesarean section: a case report. Aust N Z J Obstet Gynaecol 1996;36(1):17-9. doi: 10.1111/j.1479-828X.1996.tb02914.x.

[2] Broadway J. Acute inversion of the uterus. Anaesthesia 1989: p. 167-8.

[3] Davis GH. Acute inversion of the uterus, with the report of four cases. Am J Obstet \& Gynecol 1933;26(2):24954.

[4] Cindr J, Cepicksy P. Torsion of the uterus due to uterine inversion during caesarean section. Cesk Gynekol 1989;54(9):690-2.

[5] De Rezende J, Barcellos JM. Uterine inversion in cesarean section due to placenta accreta. Rev Ginecol Obstet (Sao Paulo) 1965;117(1):38-45.

[6] Sivasuriya M, Herath HP. Inversion of cervix uteri at caesarean section. Br Med J 1976;1(6012):746-7.

[7] Turner RJ, Lambrost M, Holmes C, et al. The effects of sevoflurane on isolated gravid human myometrium. Anaesth Intensive Care 2002;30(5):591-6.

[8] Baskett TF. Acute uterine inversion: a review of 40 cases. J Obstet Gynaecol Can 2002;24(12):953-6.

[9] Banerjee N, Deka D, Roy KK, et al. Inversion of uterus during cesarean section. Eur J Obstet Gynecol Reprod Biol 2000;91(1):75-7. doi: 10.1016/S03012115(99)00225-0.

[10] Rudloff U, Joels LA, Marshall N. Inversion of the uterus at caesarean section. Arch Gynecol Obstet 2004;269(3):224-6. doi: 10.1007/s00404-003-0565-y.

[11] Emmott RS, Bennett A. Acute inversion of the uterus at caesarean section. Anaesthesia 1988;43(2):118-20. doi: 10.1111/j.1365-2044.1988.tb06717.x.

[12] Terp MR, Rasmussen KL. Uterine inversion during caesarean section. Acta Obstet Gynecol Scand 1998;77(7):788-9.

[13] Studzinski Z, Branicka D. Acute complete uterine inversion-case report. Ginekol Pol 2001;72(11):881-4.

[14] Khalil A, Raafat A, Kalleja-Agius J, et al. Cardiac arrest associated with uterine inversion during caesarean section. J Obstet Gynaecol 2006;26(7):696-7. doi: 10.1080/01443610600929888. 